\title{
Vascular aging, the vascular cytoskeleton and aortic stiffness
}

\author{
Lova Prasadareddy Kajuluri ${ }^{1+} \odot$, Kuldeep Singh ${ }^{1,2+} \odot$, Kathleen G Morgan ${ }^{1}{ }^{*}(\mathbb{0}$ \\ ${ }^{1}$ Department of Health Sciences, Boston University, Boston, MA 02215, USA \\ ${ }^{2}$ CSIR-Institute of Himalayan Bioresource Technology, Palampur, Himachal Pradesh 176061, India
}

${ }^{\dagger}$ These authors contributed equally to this work.

*Correspondence: Kathleen G Morgan, Department of Health Sciences, Boston University, Boston, MA 02215, USA. kmorgan@ bu.edu

Academic Editor: Akiko Mammoto, Medical College of Wisconsin, USA

Received: February 06, 2021 Accepted: April 07, 2021 Published: June 30, 2021

Cite this article: Kajuluri LP, Singh K, Morgan KG. Vascular aging, the vascular cytoskeleton and aortic stiffness. Explor Med. 2021;2:186-197. https://doi.org/10.37349/emed.2021.00041

\begin{abstract}
Vascular aging, aortic stiffness and hypertension are mechanistically interrelated. The perspective presented here will focus mainly on the molecular mechanisms of age-associated increases in the stiffness of the vascular smooth muscle cell (VSMC). This review will highlight the mechanisms by which the VSMC contributes to disorders of vascular aging. Distinct functional sub-components of the vascular cell and the molecular mechanisms of the protein-protein interactions, signaling mechanisms and intracellular trafficking processes in the setting of the aging aorta will be detailed.
\end{abstract}

\section{Keywords}

Vascular aging, cytoskeleton, focal adhesion, aortic stiffness

\section{Introduction}

\section{Definition and quantification of vascular aging}

Vascular aging has been stated to be a key clinical factor in the determination of the health of the vascular system [1]. With age there is known to be a trend, dependent on the patient's lifestyle, toward progressive remodeling and, especially, stiffening of the vasculature [2]. This is of note because vascular stiffening can be associated with, and is thought to be a cause of, hypertension, stroke, and vascular dementia [3]. The relative pace of vascular aging has been described by the concept of vascular age determination according to comparison with key clinical guidelines to indicate the relative slowing or acceleration of vascular function deterioration [1]. Specifically, high-resolution B-mode ultrasound has been used to measure carotid artery intima-media thickness (CIMT) [4] and vascular age has been defined by comparison to the age at which the composite CIMT measurements would represent the median value in the previously published Atherosclerosis Risk in Communities study [4-6]. Thus, clinically, vascular aging is quantifiable, but in order to design therapeutics to prevent or reverse vascular aging, the cellular and molecular basis must also be determined. 
Hypertension and aortic stiffness during aging are interrelated. It has been reported for the Framingham Heart Study Offspring cohort that increased in vivo aortic stiffness [measured by carotid femoral pulse wave velocity (CFPWV)] is a strong predictor of the progression of hypertension [7] and has been suggested to be "an inevitable accompaniment of isolated hypertension" [8]. In the large arteries such as the aorta and carotid, an increase in arterial stiffness is known to parallel general vascular aging and to be a major predictor of cerebral bleeds and end organ damage to the high-flow organs, the brain, heart, and kidneys, in general [9]. Furthermore, the stiffness of the aorta is a quantifiable biomechanical property of aortic tissue and readily amenable to the development of prototype potential therapeutic agents. Thus, we will focus here specifically on aortic stiffness during aging.

\section{Components of vascular stiffening with age}

Both cellular and acellular factors are known to be involved in aging-associated changes in stiffness of blood vessels. It is well established that aging leads to a stiffening, specifically, of the extracellular matrix (ECM) via collagen crosslinking and elastin degradation [10-13]. Much has been previously written on this subject and hence, will not be discussed in detail here.

More recently, it has been shown that the vascular smooth muscle cell (VSMC) [14-17] also undergoes aging-dependent changes that increase its stiffness and, as a result, the stiffness of the aortic wall. Within the VSMC, the activity of the contractile filaments as well as the molecular signaling pathways that regulate actin polymerization and focal adhesion (FA) signaling, are sources of increases in vascular stiffness with age [18]. It has only recently been recognized that regulation of the stiffness of the cytoskeleton of the VSMC can contribute up to 50\% of total aortic stiffness even in young adult aortas in mouse models [16]. Similar quantitative biomechanical data are much needed from live human tissues. In addition to VSMC stiffness, increased VSMC adhesion to the ECM has been shown to contribute to increased aortic stiffness with aging [19]. Furthermore, both VSMC stiffness and VSMC adhesion, but not changes in ECM composition, have been shown to potentially contribute to increased aortic stiffness in hypertension, which further increases with hypertensive aging [20, 21].

Since the endothelium is only a monolayer of cells, at first glance it may seem unlikely that its structure would cause major changes in the overall stiffness of the wall; however, the endothelium releases vasodilators (nitric oxide (NO) [22-24], prostacyclin [25], endothelium-derived hyperpolarizing factors (EDHFs, 11, 12-epoxyeicosatrienoic acid [26, 27]) and vasoconstrictors (endothelin [28] and thromboxane A2 [29]) that regulate the activity of the contractile filaments in underlying VSMCs, generally by affecting the intracellular calcium concentrations [30]. In healthy young and adult individuals, a balance between vasodilators and vasoconstrictors allows the vessel to undergo changes in its diameter that modulate the incoming pulsatile blood flow, however, this function is largely lost with advancing age, resulting in stiffening of the vascular wall and hypertension [31, 32]. Age-induced loss of endothelial function, particularly loss of endothelium-dependent vasodilation occurs mainly because of reduced nitric oxide bioavailability triggered by an increased stiffness of the endothelial cell cortex [33, 34] and increased oxidative stress in the vasculature [35]. Increased stiffness of the endothelial cell cortex decreases the release of NO from the endothelium [36] and increased oxidative stress causes an increase in reactive oxygen species (ROS) molecules, such as superoxide radicals, that scavenge nitric oxide [37].

The outer adventitial layer of aorta confers structural integrity and contains a cellular repertoire of fibroblasts, macrophages, dendritic cells, mast cells and vascular progenitor cells etc. [38] that may also dynamically alter the total aortic stiffness. Though the collagen fibers produced by adventitial fibroblasts are clearly involved in regulating the stiffness [39], the contribution of cytoskeletal structures of adventitial cells to aortic stiffness is unknown.

\section{In vitro handling of experimental tissues}

There exists a large literature on changes in aortic stiffness due to aging of the matrix layers of the aorta [40-42] and thus will not be covered in detail here. Much less is known about aging of the VSMCs since, experimentally, the majority of studies on matrix utilize tissues from slaughterhouses that are 
studied hours, if not days, after transport to the research lab. Under these conditions, the VSMCs are likely malfunctioning, or are simply dead. It may be reasonable to assume that the matrix is preserved in the native state. However, it would also be worthwhile to determine whether post-translational modifications, fibroblast function, etc., are preserved in the matrix with long-term storage after removal from the animal. Additionally, cultured, but growth-arrested, VSMCs are also often used for study of the native aortic VSMCs but, clearly, even though they are growth-arrested, the cells will differ in morphology, and relative abundance of isoforms of contractile proteins and contractile ability, compared to the native cells in the aorta of a living human. Thus, we will focus here on the reported properties and aging of freshly isolated or in situ VSMCs where possible.

\section{Subcellular structures responsible for regulated contractility and stiffness of the vascular cell}

In both the human as well as mouse models of aging, increased aortic stiffness is associated with a damaging increase in the pulsatility of the blood sent from the heart to the high flow organs, especially the brain, kidney, and the heart [40,43-45]. Hence, the subcellular sites of generation of these sources of increased stiffness are important to identify since they may be sites where modulation may be therapeutically useful.

\section{The contractile filaments}

The attachment of the smooth muscle myosin heads to the actin filaments in the contractile filaments leads to the generation of contractile force, vascular tone, and, also for the duration of the attachment, it increases the stiffness of the cell $[46,47]$. Drugs that regulate smooth muscle myosin activity will regulate both stiffness and steady state blood pressure; however, the contractile filaments may not be a good choice for the design of therapeutic targets to decrease aortic stiffness since vascular tone and contractility will be decreased in parallel with stiffness. Though there are no reports of altered myosin activity with aging, elevated levels of alpha smooth muscle actin have been shown to contribute to increased VSMC stiffness with ageing [14]. Additionally, age-dependent increases in actin cytoskeletal stiffness have been shown to be positively associated with pro-fibrotic transforming growth factor (TGF)- $\beta$ expression and this is reinforced through mechanosensitive integrin receptors on the cell surface [48].

\section{The nonmuscle actin cytoskeleton}

VSMCs, unlike striated muscle cells, lack tendons, but transmit contractile force through the non-muscle cytoskeleton to FAs that span the plasmalemma and communicate force and stiffness to the ECM (Figure 1). This allows the matrix between cells to act as a sort of intramuscular tendon and to communicate contractile forces within the blood vessel or organ. VSMCs contain 3 isoforms of actin: alpha smooth muscle actin, beta nonmuscle actin and gamma nonmuscle actin [46, 49]. Alpha actin is located in the contractile filaments where it interacts with smooth muscle myosin cross-bridges during contractile activation. Beta actin is localized around the dense bodies, intracellular sites where contractile filaments terminate and gamma actin is present in the cell cortex $[50,51]$. Force generated by the contractile filaments is transmitted from the dense bodies to a diffuse subplasmalemmal nonmuscle cortex containing nonmuscle gamma actin and the FAs. Both the beta actin cytoskeleton and cortical gamma actin cytoskeleton as well as the contractile filaments contribute to total smooth muscle stiffness.

\section{FA dynamics}

FAs connect the vascular smooth muscle cytoskeleton to the ECM, but unlike the connection of striated muscle cells to tendons, vascular FAs are dynamic, multiprotein structures regulated by biomechanical forces as well as biochemical signaling $[64,65]$. Furthermore, when mutations occur in the ECM protein, fibrillin-1, which normally links the vascular FAs and the extracellular vascular matrix, this can result in thoracic aortic aneurysms and dissections [66].

As indicated in Figure 1, the plasmalemma is spanned by integrin complexes connecting, extracellularly, with matrix molecules [53] and, intracellularly, with cytoskeletal complexes [54]. An important cluster 
(Figure 1) of FA molecules, including talin, directly contact the integrins [67] and, also link to FAK [68]. FAK, in turn links to Paxillin, and both FAK and Paxillin are phosphorylated by Src in a tension-dependent manner [56]. The posttranslational modification of these molecules and the interactions of these proteins has been observed to be quite dynamic in young mouse aortas as well as the smooth muscle of airways in young mice [56, 69-71]. Vasoconstrictors and other agonists can increase protein-protein interactions, and VSMC adhesion to ECM accompanied by cytoskeletal remodeling and hence, increase stiffness [17, 18, 72]. However, it has been observed in mouse models that the dynamic nature of these signaling mechanisms, which provides a sort of shock absorber for the cytoskeleton, is diminished by age [18] and that this contributes to the increased stiffness of aged aortas. Again, these concepts are, thus far, based on animal studies and similar studies using in human blood vessels are greatly needed.

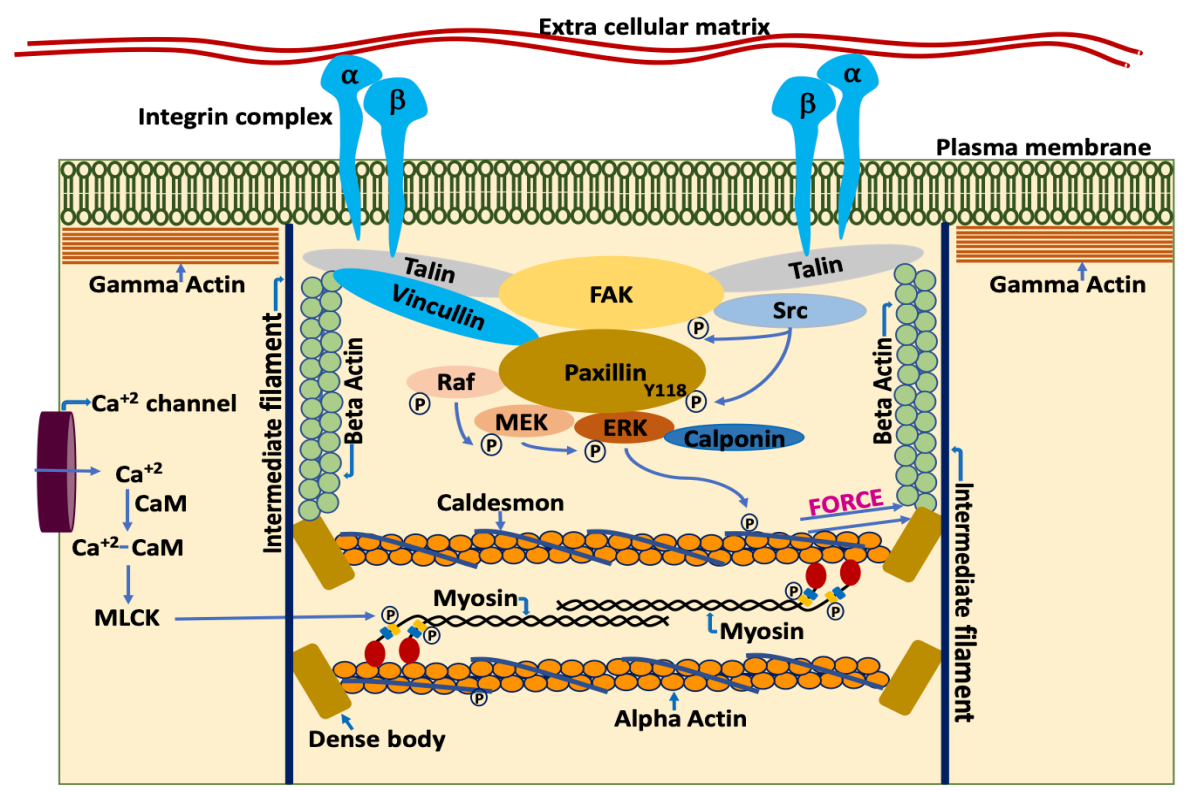

Figure 1. Schematic representation of components of the VSMC by which it regulates contractility and stiffness. The smooth muscle cell plasma membrane is spanned by FA complexes containing, among many other proteins, talin, vinculin, FA kinase (FAK), and integrins [52]. Cytoskeletal proteins of the FA complexes connect to the membrane-spanning integrins, composed of alpha and beta integrin heterodimers. On the cytoplasmic side, the FAs connect to the actin cytoskeletal filaments. Thus, the integrin complex connects the interior of the cell to the ECM allowing cell-matrix communication and signaling [53, 54]. Contractile force is generated by the actomyosin cross bridge cycle. During the cross-bridge cycle, force is generated by movement of myosin head domains while they are attached to the actin filaments. Acto-myosin cross bridge cycling is a tightly regulated process, involving both the thin and thick filaments. Thin filament regulation, in part, involves the blocking of myosin attachment sites on F-actin by caldesmon [55]. Caldesmon, in turn, is regulated by a complex, Src dependent signaling cascade. Src dependent phosphorylation of paxillin at Y118 allows the binding of rapidly accelerated fibrosarcoma (Raf) and extracellular signal-regulated kinase (ERK) to mitogen-activated protein kinase kinase (MEK) bound paxillin [56]. The formation of this complex leads to the activation of MEK by Raf and ERK transphosphorylation by active MEK. Subsequently, activated ERK translocates to, and phosphorylates, caldesmon [57]. Once phosphorylated, caldesmon undergoes a conformation change in its structure and no longer blocks the myosin attachment sites on F-actin. This sequence of events, then promotes acto-myosin interaction. However, attachment of the myosin head to F-actin is also regulated by phosphorylation of the myosin regulatory light chain (MLC), leading to additional signaling cascades described as thick filament regulation [58]. For example, increased intracellular calcium levels during agonistinduced opening of calcium channels in the plasmalemma leads to the formation of calcium-calmodulin complexes which then activates myosin light chain kinase (MLCK) [59-61]. Active MLCK then phosphorylates the myosin light chains which activates myosin ATPase activity [62]. Increased myosin ATPase activity leads to a conformational change in the head of myosin and promotes the attachment of myosin to actin in the strong binding conformation. Force generated during acto-myosin interaction is transmitted to dense bodies and through the nonmuscle actin cytoskeleton, to FA complexes, including the transmembrane integrins and, subsequently, to the ECM and the vessel wall $[46,63]$. Simultaneous contraction of the VSMCs in the vessel wall leads to vascular constriction, which, when increased in extent or duration also leads to increased pathologies of hypertension and vascular stiffness [46]

Cytoskeletal elements also serve the function of regulating the formation of signaling complexes that, in turn, also regulate stiffness and contractility of the muscle cell. The Src dependent phosphorylation of Paxillin at Y118 is critical in regulating the scaffolding property of Paxillin, bringing together Raf, MEK and ERK [56] and leading to the phosphorylation of caldesmon [73] an actin binding protein that acts in a manner analogous to that of troponin in striated muscle and directly regulates the activation of the contractile filaments. ERK, when phosphorylated by MEK, translocates to the actin filaments of smooth muscle cells 
where it phosphorylates the inhibitory protein, caldesmon, causing a conformational change that disinhibits the contractile filaments [57]. This signaling pathway is often referred to as "thin filament regulation" in contrast to the parallel pathway of "thick filament regulation" by which a Ca dependent activation of MLCK leads to phosphorylation of the $20 \mathrm{kDa}$ myosin light chains and activation of myosin motor activity. Both thin filament and thick filament regulation are needed for maximal contractile activation of the VSMC [46]. Importantly, both cross-bridge attachment in the contractile filaments (thick filament regulation) and the assembly of the ECM-integrin-cytoskeletal subplasmalemmal protein complexes (FA dynamics) have been shown to regulate the stiffness of the VSMC [16, 74-76], particularly in the proximal aorta.

\section{Cadherins}

Unlike integrins which mediate cell-matrix attachment, cadherins mediates cell-cell attachment. Cadherins are calcium binding transmembrane proteins that connect internally to the actin cytoskeleton through adherin junctions composed mainly of catenins [77]. N-cadherin is the predominant cadherin that is expressed in VSMCs whose density and clustering was shown to increase with agonist treatment [78]. Both integrins and cadherins have been shown to engage in crosstalk mediating the mechanosignaling and determining the localization of cellular forces; however, most of these studies were performed on cell types other than VSMCs [79]. Future studies are required to understand how Integrins and cadherins crosstalk in regulating the contractile force transmission between cell-cell and cell-ECM junctions and how this would regulate cell stiffness.

\section{Other cytoskeletal elements}

Other structural components of the contractile smooth muscle, such as intermediate filaments, to the best of our knowledge, have not been studied in the context of vascular stiffness and aging and, microtubules are scarce in contractile VSMCs and seem to have little acute function [80, 81].

\section{Epigenetic changes}

Epigenetic alterations with aging have emerged as one of the crucial events that cause cardiovascular pathologies which include, among many, the stiffening of the aorta. Epigenetic changes modulate the expression of genes. These include DNA methylation, histone acetylation and chromatin remodeling. Long non-coding RNAs and short non-coding RNAs [microRNAs (miRs)] also act as epigenetic effectors [82]. In smooth muscle cells, methylation status of genes is regulated by DNA methyl transferases (DNMT3A, DNMT3B, DNMT1) and Ten-eleven translocation (TET) proteins. TET2 was shown to be a master epigenetic regulator of smooth muscle cell phenotypic modulation [83]. However, the role of TETs in cardiovascular aging remains elusive. A previous report from our lab showed DNA hypomethylation of miR-203 increased stiffness of the aorta with aging. This epigenetic change increased the expression of miR-203, which down regulates Src, a key tyrosine kinase required for FA signaling. Loss of FA signaling resulted in increased aortic stiffness [17]. Reduced expression of miR-92a with age also was shown to associate with increased aortic stiffness [84]. A few other studies also reported age dependent increase in aortic stiffening caused by epigenetic alterations. However, an increase in ECM stiffness [85] was shown as the underlying molecular mechanism responsible for the observed effect. Further studies are required to understand how epigenetic alterations affect the VSMC cytoskeleton with aging and their impact on aortic stiffness.

\section{Changes in VSMC function with aging and implications for potential therapeutic target development}

In the young adult mouse model, interactions between components of the cytoskeleton are dynamic, transient and reversible and do not lead to lasting changes in stiffness (Figure 2). But, as described above, our group has found that in aged animals, some cytoskeletal components become attached in a sustained manner, increasing the stiffness of the tissue. As a possible first step in a therapeutic approach, synthesized peptide decoy inhibitors of cytoskeletal stiffness have been produced [18] to try to reverse aging-induced increases in vascular stiffness. The peptides have been made as mimics of part of the protein sequence of cytoskeletal 
proteins, such as talin or vinculin, but lacking a binding site to their downstream effector. In this way they compete with endogenous molecules and prevent those molecules from bridging parts of the cytoskeleton. This results in a significant decrease in aortic stiffness, at least as tested ex vivo.
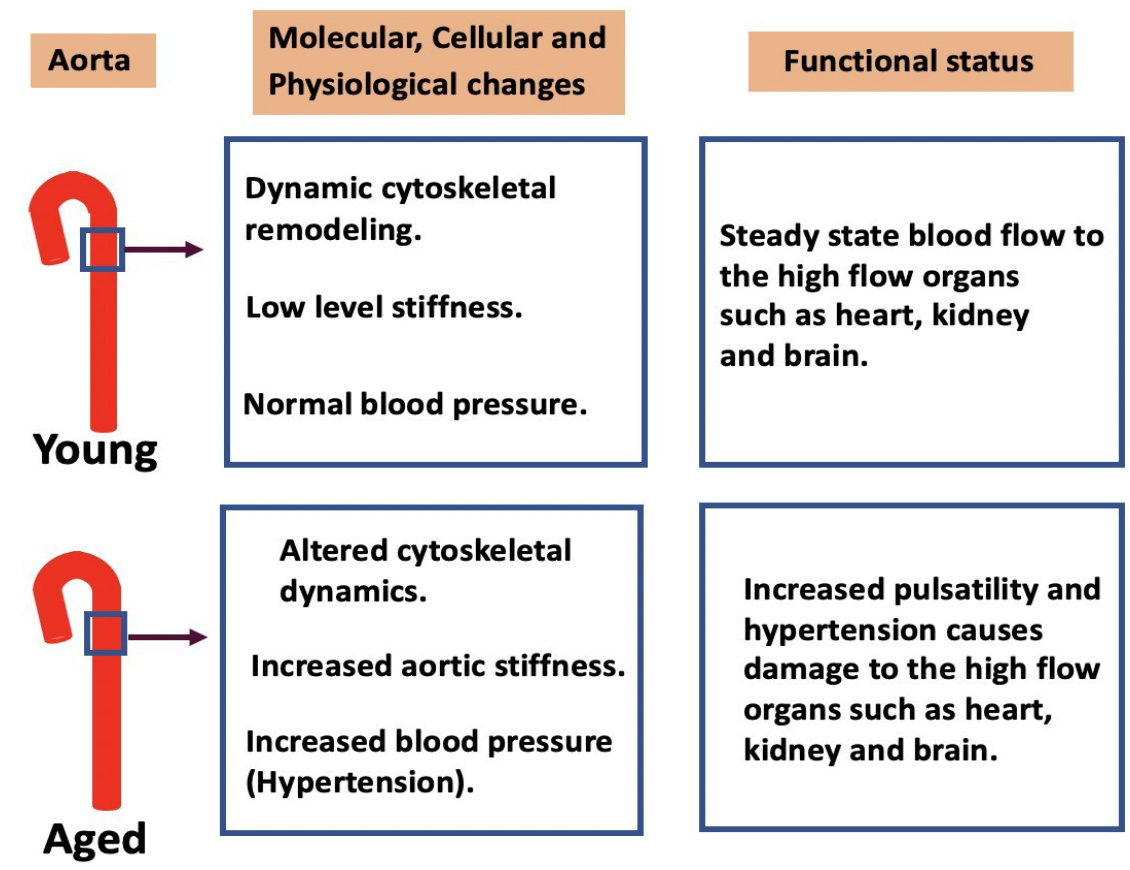

Figure 2. Cytoskeletal dynamics in the aorta with ageing and functional consequences. In young aortas dynamic cytoskeletal remodeling maintains low levels of stiffness and normal blood pressure which allow normal blood flow to the high flow organs such as heart, kidney, and brain. With advancing age, a decrease in cytoskeletal dynamics increases the stiffness of the aortic wall. This causes an increased pulsatility of the blood flow leading to damage of the end organs. Therapeutic interventions are required to prevent age-related adverse cardiovascular effects associated with vascular stiffness. Peptides that reduce stiffness by blocking cytoskeletal interactions or other novel approaches are of interest as future potential therapeutics

It is important to point out that these decoy peptides were designed to be targeted to the aorta but, in theory, it should also be possible to design a variant of these peptides to target molecular interactions in the peripheral vasculature or the resistance vessels and to decrease blood pressure rather than aortic stiffness. The vasoactive peptide approach is effective in decreasing vascular contractility and hence could be useful to tackle hypertension, but a means of successfully targeting the peptides to specific resistance vessel beds would need to be developed. Nicholson et al. [18] demonstrated that the peptides can be loaded onto microbubbles for tissue delivery, and subsequently burst by ultrasound to load the peptides into VSMCs. However, considerable work is needed to determine if ultrasound targeting of these peptide-loaded microbubbles can be used effectively in vivo, particularly in the human.

\section{Conclusions and future approaches}

Value of cytoskeletal targets for future drug development

Thus far few, if any, cytoskeletal targets have been identified for the development of potential therapeutics to treat or prevent hypertension or aortic stiffness. However, the studies cited above provide a limited proof of concept that such targets may be useful as prototype therapeutic approaches for the treatment of, not only hypertension, but also aortic stiffness associated with aging.

\section{Future approaches}

Recently, basic science investigators interested in molecular mechanisms of arterial stiffness have asked the question of whether sex-specific differences exist. Indeed, many differences between the sexes have been reported [86, 87], at least in animal models, and this line of investigation should be expanded. However, as mentioned above, because of species-specific differences, any broad conclusions between human and animal models on sex-related differences need to be made with great caution. 
As most of the published aortic stiffness research work has used cells and tissues obtained from nonhuman origin, it may not directly lead to therapeutic interventions to treat increased aortic stiffness in humans. Cells and tissues derived from human subjects may provide better insights into understanding the age dependent increase in aortic stiffness but are difficult to obtain. Patient-derived induced pluripotent stem cells (iPSCs) may provide a way to study vascular diseases as these cells can carry pathological features similar to those in the human tissues [88]. Multiple different induction media and protocols have been used to derive VSMCs from patient iPSCs [89]. This has been a useful approach to model for certain vascular pathologies such as Hutchison Gilford Progeria Syndrome (HGPS) [90, 91], atherosclerosis [92], aortic aneurysm [93], supravalvular aortic stenosis [94], and hypertension [95]. Though there are challenges associated with generation of lineage-specific and mature VSMCs from iPSCs that match the in vivo counterparts [88, 89], iPSC-VSMCs could help understand the molecular mechanisms associated with aortic stiffening and to screen drugs for potential therapeutic interventions.

\section{Abbreviations}

ECM: extracellular matrix

ERK: extracellular signal-regulated kinase

FA: focal adhesion

FAK: focal adhesion kinase

iPSCs: induced pluripotent stem cells

MEK: mitogen-activated protein kinase kinase

miRs: microRNAs

MLCK: myosin light chain kinase

Raf: rapidly accelerated fibrosarcoma

TET: Ten-eleven translocation

VSMC: vascular smooth muscle cell

\section{Declarations}

\section{Author contributions}

LPK co-wrote the manuscript, prepared figures, and conceived the concepts included. KS co-wrote the manuscript and conceived the concepts. KGM co-wrote the manuscript and conceived the concepts.

\section{Conflicts of interest}

The authors declare that they have no conflicts of interest.

\section{Ethical approval}

Not applicable.

\section{Consent to participate}

Not applicable.

\section{Consent to publication}

Not applicable.

\section{Availability of data and materials}

Not applicable. 


\section{Funding}

This study was supported by National Institutes of Health grant NIH NIA AG053274. The funders had no role in study design, data collection and analysis, decision to publish, or preparation of the manuscript.

\section{Copyright}

(C) The Author(s) 2021.

\section{References}

1. Perk J, De Backer G, Gohlke H, Graham I, Reiner Z, Verschuren WM, et al. European Guidelines on cardiovascular disease prevention in clinical practice (version 2012): the fifth joint task force of the European society of cardiology and other societies on cardiovascular disease prevention in clinical practice (constituted by representatives of nine societies and by invited experts). Atherosclerosis. 2012;223:1-68.

2. Guzik TJ, Touyz RM. Oxidative Stress, Inflammation, and vascular aging in hypertension. Hypertension. 2017;70:660-7.

3. Mogi M. Could management of blood pressure prevent dementia in the elderly? Clin Hypertens. 2019;25:27.

4. Stein JH, Fraizer MC, Aeschlimann SE, Nelson-Worel J, McBride PE, Douglas PS. Vascular age: integrating carotid intima-media thickness measurements with global coronary risk assessment. Clin Cardiol. 2004;27:388-92.

5. Brocca L, McPhee JS, Longa E, Canepari M, Seynnes O, De Vito G, et al. Structure and function of human muscle fibres and muscle proteome in physically active older men. J Physiol. 2017;595:4823-44.

6. Stein JH, Korcarz CE, Mays ME, Douglas PS, Palta M, Zhang H, et al. A semiautomated ultrasound border detection program that facilitates clinical measurement of ultrasound carotid intima-media thickness. J Am Soc Echocardiogr. 2005;18:244-51.

7. Kaess BM, Rong J, Larson MG, Hamburg NM, Vita JA, Levy D, et al. Aortic stiffness, blood pressure progression, and incident hypertension. Jama. 2012;308:875-81.

8. Mitchell GF. Arterial stiffness and hypertension: chicken or egg? Hypertension. 2014;64:210-4.

9. Vasan RS, Short MI, Niiranen TJ, Xanthakis V, DeCarli C, Cheng S, et al. Interrelations between arterial stiffness, target organ damage, and cardiovascular disease outcomes. J Am Heart Assoc. 2019;8:e012141.

10. Oh YS, Berkowitz DE, Cohen RA, Figueroa CA, Harrison DG, Humphrey JD, et al. A special report on the NHLBI initiative to study cellular and molecular mechanisms of arterial stiffness and its association with hypertension. Circ Res. 2017;121:1216-8.

11. Díez J. Arterial stiffness and extracellular matrix. Adv Cardiol. 2007;44:76-95.

12. Wagenseil JE, Mecham RP. Vascular extracellular matrix and arterial mechanics. Physiol Rev. 2009;89: 957-89.

13. Fleenor BS, Marshall KD, Durrant JR, Lesniewski LA, Seals DR. Arterial stiffening with ageing is associated with transforming growth factor- $\beta 1$-related changes in adventitial collagen: reversal by aerobic exercise. J Physiol. 2010;588:3971-82.

14. Qiu H, Zhu Y, Sun Z, Trzeciakowski JP, Gansner M, Depre C, et al. Short communication: vascular smooth muscle cell stiffness as a mechanism for increased aortic stiffness with aging. Circ Res. 2010;107:615-9.

15. Morales-Quinones M, Ramirez-Perez FI, Foote CA, Ghiarone T, Ferreira-Santos L, Bloksgaard M, et al. LIMK (LIM kinase) inhibition prevents vasoconstriction- and hypertension-induced arterial stiffening and remodeling. Hypertension. 2020;76:393-403.

16. Gao YZ, Saphirstein RJ, Yamin R, Suki B, Morgan KG. Aging impairs smooth muscle-mediated regulation of aortic stiffness: a defect in shock absorption function? Am J Physiol Heart Circ Physiol. 2014;307: H1252-61. 
17. Nicholson CJ, Seta F, Lee S, Morgan KG. MicroRNA-203 mimics age-related aortic smooth muscle dysfunction of cytoskeletal pathways. J Cell Mol Med. 2017;21:81-95.

18. Nicholson CJ, Singh K, Saphirstein RJ, Gao YZ, Li Q, Chiu JG, et al. Reversal of aging-induced increases in aortic stiffness by targeting cytoskeletal protein-protein interfaces. J Am Heart Assoc. 2018;7:e008926.

19. Zhu Y, Qiu H, Trzeciakowski JP, Sun Z, Li Z, Hong Z, et al. Temporal analysis of vascular smooth muscle cell elasticity and adhesion reveals oscillation waveforms that differ with aging. Aging Cell. 2012;11:741-50.

20. Sehgel NL, Zhu Y, Sun Z, Trzeciakowski JP, Hong Z, Hunter WC, et al. Increased vascular smooth muscle cell stiffness: a novel mechanism for aortic stiffness in hypertension. Am J Physiol Heart Circ Physiol. 2013;305:H1281-7.

21. Sehgel NL, Sun Z, Hong Z, Hunter WC, Hill MA, Vatner DE, et al. Augmented vascular smooth muscle cell stiffness and adhesion when hypertension is superimposed on aging. Hypertension. 2015;65:370-7.

22. Furchgott RF, Zawadzki JV. The obligatory role of endothelial cells in the relaxation of arterial smooth muscle by acetylcholine. Nature. 1980;288:373-6.

23. Arnold WP, Mittal CK, Katsuki S, Murad F. Nitric oxide activates guanylate cyclase and increases guanosine 3':5'-cyclic monophosphate levels in various tissue preparations. Proc Natl Acad Sci U S A. 1977;74:3203-7.

24. Ignarro LJ, Byrns RE, Buga GM, Wood KS. Endothelium-derived relaxing factor from pulmonary artery and vein possesses pharmacologic and chemical properties identical to those of nitric oxide radical. Circ Res. 1987;61:866-79.

25. Rubin LJ, Groves BM, Reeves JT, Frosolono M, Handel F, Cato AE. Prostacyclin-induced acute pulmonary vasodilation in primary pulmonary hypertension. Circulation. 1982;66:334-8.

26. Archer SL, Gragasin FS, Wu X, Wang S, McMurtry S, Kim DH, et al. Endothelium-derived hyperpolarizing factor in human internal mammary artery is 11,12-epoxyeicosatrienoic acid and causes relaxation by activating smooth muscle BK(Ca) channels. Circulation. 2003;107:769-76.

27. Miura H, Wachtel RE, Liu Y, Loberiza FR Jr, Saito T, Miura M, et al. Flow-induced dilation of human coronary arterioles: important role of $\mathrm{Ca}^{2+}$-activated $\mathrm{K}^{+}$channels. Circulation. 2001;103:1992-8.

28. Yanagisawa M, Kurihara H, Kimura S, Tomobe Y, Kobayashi M, Mitsui Y, et al. A novel potent vasoconstrictor peptide produced by vascular endothelial cells. Nature. 1988;332:411-5.

29. Altiere RJ, Kiritsy-Roy JA, Catravas JD. Acetylcholine-induced contractions in isolated rabbit pulmonary arteries: role of thromboxane A2. J Pharmacol Exp Ther. 1986;236:535-41.

30. Sandoo A, van Zanten JJ, Metsios GS, Carroll D, Kitas GD. The endothelium and its role in regulating vascular tone. Open Cardiovasc Med J. 2010;4:302-12.

31. Donato AJ, Machin DR, Lesniewski LA. Mechanisms of dysfunction in the aging vasculature and role in age-related disease. Circ Res. 2018;123:825-48.

32. Qian H, Luo N, Chi Y. Aging-shifted prostaglandin profile in endothelium as a factor in cardiovascular disorders. J Aging Res. 2012;2012:121390.

33. Drüppel V, Kusche-Vihrog K, Grossmann C, Gekle M, Kasprzak B, Brand E, et al. Long-term application of the aldosterone antagonist spironolactone prevents stiff endothelial cell syndrome. FASEB J. 2013;27:3652-9.

34. Paar M, Pavenstädt H, Kusche-Vihrog K, Drüppel V, Oberleithner H, Kliche K. Endothelial sodium channels trigger endothelial salt sensitivity with aging. Hypertension. 2014;64:391-6.

35. Donato AJ, Eskurza I, Silver AE, Levy AS, Pierce GL, Gates PE, et al. Direct evidence of endothelial oxidative stress with aging in humans: relation to impaired endothelium-dependent dilation and upregulation of nuclear factor-kappaB. Circ Res. 2007;100:1659-66.

36. Fels J, Jeggle P, Kusche-Vihrog K, Oberleithner H. Cortical actin nanodynamics determines nitric oxide release in vascular endothelium. PLoS One. 2012;7:e41520. 
37. van der Loo B, Labugger R, Skepper JN, Bachschmid M, Kilo J, Powell JM, et al. Enhanced peroxynitrite formation is associated with vascular aging. J Exp Med. 2000;192:1731-44.

38. Tinajero MG, Gotlieb AI. Recent developments in vascular adventitial pathobiology: the dynamic adventitia as a complex regulator of vascular aisease. Am J Pathol. 2020;190:520-34.

39. Stenmark KR, Yeager ME, El Kasmi KC, Nozik-Grayck E, Gerasimovskaya EV, Li M, et al. The adventitia: essential regulator of vascular wall structure and function. Annu Rev Physiol. 2013;75:23-47.

40. Chirinos JA, Segers P, Hughes T, Townsend R. Large-artery stiffness in health and disease: JACC state-ofthe-art review. J Am Coll Cardiol. 2019;74:1237-63.

41. Humphrey JD, Tellides G. Central artery stiffness and thoracic aortopathy. Am J Physiol Heart Circ Physiol. 2019;316:H169-82.

42. Cocciolone AJ, Hawes JZ, Staiculescu MC, Johnson EO, Murshed M, Wagenseil JE. Elastin, arterial mechanics, and cardiovascular disease. Am J Physiol Heart Circ Physiol. 2018;315:H189-205.

43. Cooper LL, Mitchell GF. Aortic stiffness, cerebrovascular dysfunction, and memory. Pulse (Basel). 2016;4:69-77.

44. Knutsen RH, Beeman SC, Broekelmann TJ, Liu D, Tsang KM, Kovacs A, et al. Minoxidil improves vascular compliance, restores cerebral blood flow, and alters extracellular matrix gene expression in a model of chronic vascular stiffness. Am J Physiol Heart Circ Physiol. 2018;315:H18-32.

45. de Montgolfier O, Pouliot P, Gillis MA, Ferland G, Lesage F, Thorin-Trescases N, et al. Systolic hypertensioninduced neurovascular unit disruption magnifies vascular cognitive impairment in middle-age atherosclerotic $\mathrm{LDLr}^{-/}: \mathrm{hApoB}^{+/+}$mice. Geroscience. 2019;41:511-32.

46. Brozovich FV, Nicholson CJ, Degen CV, Gao YZ, Aggarwal M, Morgan KG. Mechanisms of vascular smooth muscle contraction and the basis for pharmacologic treatment of smooth muscle disorders. Pharmacol Rev. 2016;68:476-532.

47. Mizuno D, Tardin C, Schmidt CF, Mackintosh FC. Nonequilibrium mechanics of active cytoskeletal networks. Science. 2007;315:370-3.

48. Zhu W, Kim BC, Wang M, Huang J, Isak A, Bexiga NM, et al. TGFß1 reinforces arterial aging in the vascular smooth muscle cell through a long-range regulation of the cytoskeletal stiffness. Sci Rep. 2018;8:2668.

49. Gallant C, Appel S, Graceffa P, Leavis P, Lin JJ, Gunning PW, et al. Tropomyosin variants describe distinct functional subcellular domains in differentiated vascular smooth muscle cells. Am J Physiol Cell Physiol. 2011;300:C1356-65.

50. Kim HR, Gallant C, Leavis PC, Gunst SJ, Morgan KG. Cytoskeletal remodeling in differentiated vascular smooth muscle is actin isoform dependent and stimulus dependent. Am J Physiol Cell Physiol. 2008;295:C768-78.

51. Yamin R, Morgan KG. Deciphering actin cytoskeletal function in the contractile vascular smooth muscle cell. J Physiol. 2012;590:4145-54.

52. Romer LH, Birukov KG, Garcia JG. Focal adhesions: paradigm for a signaling nexus. Circ Res. 2006;98:606-16.

53. Clyman RI, McDonald KA, Kramer RH. Integrin receptors on aortic smooth muscle cells mediate adhesion to fibronectin, laminin, and collagen. Circ Res. 1990;67:175-86.

54. Critchley DR. Focal adhesions-the cytoskeletal connection. Curr Opin Cell Biol. 2000;12:133-9.

55. Earley JJ, Su X, Moreland RS. Caldesmon inhibits active crossbridges in unstimulated vascular smooth muscle: an antisense oligodeoxynucleotide approach. Circ Res. 1998;83:661-7.

56. Min J, Reznichenko M, Poythress RH, Gallant CM, Vetterkind S, Li Y, et al. Src modulates contractile vascular smooth muscle function via regulation of focal adhesions. J Cell Physiol. 2012;227:3585-92.

57. Dessy C, Kim I, Sougnez CL, Laporte R, Morgan KG. A role for MAP kinase in differentiated smooth muscle contraction evoked by alpha-adrenoceptor stimulation. Am J Physiol. 1998;275:C1081-6. 
58. Horowitz A, Menice CB, Laporte R, Morgan KG. Mechanisms of smooth muscle contraction. Physiol Rev. 1996;76:967-1003.

59. Dabrowska R, Sherry JM, Aromatorio DK, Hartshorne DJ. Modulator protein as a component of the myosin light chain kinase from chicken gizzard. Biochemistry. 1978;17:253-8.

60. Adelstein RS, Klee CB. Purification and characterization of smooth muscle myosin light chain kinase. J Biol Chem. 1981;256:7501-9.

61. Ikebe M, Hartshorne DJ. Effects of $\mathrm{Ca}^{2+}$ on the conformation and enzymatic activity of smooth muscle myosin. J Biol Chem. 1985;260:13146-53.

62. Chacko S, Conti MA, Adelstein RS. Effect of phosphorylation of smooth muscle myosin on actin activation and $\mathrm{Ca}^{2+}$ regulation. Proc Natl Acad Sci U S A. 1977;74:129-33.

63. Gabella G. Structural apparatus for force transmission in smooth muscles. Physiol Rev. 1984;64:455-77.

64. Hill MA, Sun Z, Martinez-Lemus L, Meininger GA. New technologies for dissecting the arteriolar myogenic response. Trends Pharmacol Sci. 2007;28:308-15.

65. Ohanian J, Pieri M, Ohanian V. Non-receptor tyrosine kinases and the actin cytoskeleton in contractile vascular smooth muscle. J Physiol. 2015;593:3807-14.

66. Milewicz DM, Trybus KM, Guo DC, Sweeney HL, Regalado E, Kamm K, et al. Altered smooth muscle cell force generation as a driver of thoracic aortic aneurysms and dissections. Arterioscler Thromb Vasc Biol. 2017;37:26-34.

67. Calderwood DA, Yan B, de Pereda JM, Alvarez BG, Fujioka Y, Liddington RC, et al. The phosphotyrosine binding-like domain of talin activates integrins. J Biol Chem. 2002;277:21749-58.

68. Klapholz B, Brown NH. Talin-the master of integrin adhesions. J Cell Sci. 2017;130:2435-46.

69. Tang D, Mehta D, Gunst SJ. Mechanosensitive tyrosine phosphorylation of paxillin and focal adhesion kinase in tracheal smooth muscle. Am J Physiol. 1999;276:C250-8.

70. TangDD, GunstSJ.Selected contribution:roles of focal adhesion kinase and paxillin in the mechanosensitive regulation of myosin phosphorylation in smooth muscle. J Appl Physiol (1985). 2001;91:1452-9.

71. Poythress RH, Gallant C, Vetterkind S, Morgan KG. Vasoconstrictor-induced endocytic recycling regulates focal adhesion protein localization and function in vascular smooth muscle. Am J Physiol Cell Physiol. 2013;305:C215-27.

72. Hong Z, Sun Z, Li M, Li Z, Bunyak F, Ersoy I, et al. Vasoactive agonists exert dynamic and coordinated effects on vascular smooth muscle cell elasticity, cytoskeletal remodelling and adhesion. J Physiol. 2014;592:1249-66.

73. Katsuyama H, Wang CL, Morgan KG. Regulation of vascular smooth muscle tone by caldesmon. J Biol Chem. 1992;267:14555-8.

74. Zhou N, Lee JJ, Stoll S, Ma B, Costa KD, Qiu H. Rho kinase regulates aortic vascular smooth muscle cell stiffness via actin/SRF/myocardin in hypertension. Cell Physiol Biochem. 2017;44:701-15.

75. Rhee AY, Brozovich FV. The smooth muscle cross-bridge cycle studied using sinusoidal length perturbations. Biophys J. 2000;79:1511-23.

76. Saphirstein RJ, Gao YZ, Jensen MH, Gallant CM, Vetterkind S, Moore JR, et al. The focal adhesion: a regulated component of aortic stiffness. PLoS One. 2013;8:e62461.

77. Gumbiner BM. Regulation of cadherin-mediated adhesion in morphogenesis. Nat Rev Mol Cell Biol. 2005;6:622-34.

78. Sun Z, Li M, Li Z, Hill MA, Meininger GA. N-Cadherin, a novel and rapidly remodelling site involved in vasoregulation of small cerebral arteries. J Physiol. 2017;595:1987-2000.

79. Mui KL, Chen CS, Assoian RK. The mechanical regulation of integrin-cadherin crosstalk organizes cells, signaling and forces. J Cell Sci. 2016;129:1093-100. 
80. Blagosklonny MV, Darzynkiewicz Z, Halicka HD, Pozarowski P, Demidenko ZN, Barry JJ, et al. Paclitaxel induces primary and postmitotic G1 arrest in human arterial smooth muscle cells. Cell Cycle. 2004;3:1050-6.

81. Somlyo AV. Ultrastructure of vascular smooth muscle. In: Handbook of physiology. Witshire: John Wiley \& Sons, Inc; 1980. pp. 33-67.

82. Zhang W, Song M, Qu J, Liu GH. Epigenetic modifications in cardiovascular aging and diseases. Circ Res. 2018;123:773-86.

83. Liu R, Jin Y, Tang WH, Qin L, Zhang X, Tellides G, et al. Ten-eleven translocation-2 (TET2) is a master regulator of smooth muscle cell plasticity. Circulation. 2013;128:2047-57.

84. Hazra S, Henson GD, Morgan RG, Breevoort SR, Ives SJ, Richardson RS, et al. Experimental reduction of miR-92a mimics arterial aging. Exp Gerontol. 2016;83:165-70.

85. Hori D, Dunkerly-Eyring B, Nomura Y, Biswas D, Steppan J, Henao-Mejia J, et al. miR-181b regulates vascular stiffness age dependently in part by regulating TGF- $\beta$ signaling. PLoS One. 2017;12:e0174108.

86. Reckelhoff JF, Romero DG, Yanes Cardozo LL. Sex, oxidative stress, and hypertension: insights from animal models. Physiology (Bethesda). 2019;34:178-88.

87. Reckelhoff JF, Alexander BT. Reproducibility in animal models of hypertension: a difficult problem. Biol Sex Differ. 2018;9:53.

88. Shen M, Quertermous T, Fischbein MP, Wu JC. Generation of vascular smooth muscle cells from induced pluripotent stem cells: methods, applications, and considerations. Circ Res. 2021;128:670-86.

89. Paik DT, Chandy M, Wu JC. Patient and disease-specific induced pluripotent stem cells for discovery of personalized cardiovascular drugs and therapeutics. Pharmacol Rev. 2020;72:320-42.

90. Zhang J, Lian Q, Zhu G, Zhou F, Sui L, Tan C, et al. A human iPSC model of Hutchinson Gilford Progeria reveals vascular smooth muscle and mesenchymal stem cell defects. Cell Stem Cell. 2011;8:31-45.

91. Atchison L, Zhang H, Cao K, Truskey GA. A tissue engineered blood vessel model of hutchinson-gilford progeria syndrome using human iPSC-derived smooth muscle cells. Sci Rep. 2017;7:8168.

92. Toyohara T, Roudnicky F, Florido MHC, Nakano T, Yu H, Katsuki S, et al. Patient hiPSCs identify vascular smooth muscle arylacetamide deacetylase as protective against atherosclerosis. Cell Stem Cell. 2020;27:147-57.e7.

93. Gong J, Zhou D, Jiang L, Qiu P, Milewicz DM, Chen YE, et al. In vitro lineage-specific differentiation of vascular smooth muscle cells in response to SMAD3 deficiency: implications for SMAD3-related thoracic aortic aneurysm. Arterioscler Thromb Vasc Biol. 2020;40:1651-63.

94. Ge X, Ren Y, Bartulos O, Lee MY, Yue Z, Kim KY, et al. Modeling supravalvular aortic stenosis syndrome with human induced pluripotent stem cells. Circulation. 2012;126:1695-704.

95. Biel NM, Santostefano KE, DiVita BB, El Rouby N, Carrasquilla SD, Simmons C, et al. Vascular smooth muscle cells from hypertensive patient-derived induced pluripotent stem cells to advance hypertension pharmacogenomics. Stem Cells Transl Med. 2015;4:1380-90. 